\title{
SUTURE HAEMORRHOIDOPEXY AND ITS SHORT-TERM OUTCOME
}

\author{
Dinesh Prasad ${ }^{1}$, Kalariya Bhargav Jerambhai², Savan Jivani ${ }^{3}$
}

${ }^{1}$ Additional Professor, Department of General Surgery, Surat Municipal Institute of Medical Education and Research, Surat, Gujarat, India.

${ }^{2}$ Resident, Department of General Surgery, Surat Municipal Institute of Medical Education and Research, Surat, Gujarat, India. ${ }^{3}$ Resident, Department of General Surgery, Surat Municipal Institute of Medical Education and Research, Surat, Gujarat, India.

ABSTRACT
BACKGROUND
Since ancient times, haemorrhoids are known to be a common anorectal disease.[1] Many of the treatments have been widely
practiced since old times. In India, this condition is associated with rural areas and low socio-economic status, hence the exact
prevalence is not known. Patients usually neglect the disease because of fear to come in front of society with disease and also
hesitate to take treatment for it. This leads to progression of the disease and it become more severe.[2] Patients who had failed
medical treatment usually need surgical treatment.[3] Suture haemorrhoidopexy (Chivate's procedure) now also called as
mucorectopexy is a new surgery invented by an Indian surgeon for managing 2nd, 3rd, 4th grades of haemorrhoids with lesser
incidence of pain. It is based on the principles of blocking of blood supply and preventing the neovascularization by plication of
vessels in the rectum above dentate line at two different levels and anchoring the rectal mucosa \& sub mucosa to Parks
Ligament.[4],[5]
The objective of the study is to evaluate Chivate's new procedure of trans-anal mucorectopexy for 3rd and 4th degree
haemorrhoids for pain, bleeding, hospital stay, recurrence and complications.

\section{MATERIALS AND METHODS}

It is an observational study. A total of 35 patients with grade 3 and grade 4 haemorrhoids (symptomatic with bleeding per rectum) underwent suture mucorectopexy procedure. The study was conducted at department of general surgery, SMIMER, Surat, wherein patients presenting to us with complaints of haemorrhoids were screened and patients with 3rd and 4th degree haemorrhoids and willing to undergo surgery were selected for this study. We had collected data of 35 patients with 3rd and 4th degree haemorrhoids and operated with this procedure. The sample size has taken for convenience.

\section{RESULTS}

- Mean time required for procedure was $74.9 \mathrm{~min}$.

- Mean duration of hospital stay was 4.42 days.

- Mean time to return to normal activity was 7.2 days.

Average VAS score for post-operative pain at 24 hours was 5.5, at 72 hours was 3.4 , at 7 th day was 1.3 , at 1 month was 0.3 . Commonly reported complaints include, urinary retention- $34.2 \%(\mathrm{n}=12)$, pruritus ani- $8.5 \%(\mathrm{n}=3)$, pain after operation requiring analgesic injections $8.5 \%(n=3)$, constipation $5.71 \%(n=2)$, bleeding PR 2.85\% $(n=1)$, rehospitalization due to urinary retention $2.85 \%(\mathrm{n}=1)$.

\section{CONCLUSION}

Negligible recurrence rate on short term follow up along with lesser incidence of post-operative bleeding, minimal invasiveness with faster recovery or return to work will make Suture Haemorrhoidopexy a procedure of choice for grade II, III and IV haemorrhoids.

\section{KEY WORDS}

Suture Haemorrhoidopexy, Mucorectopexy.

HOW TO CITE THIS ARTICLE: Prasad D, Jerambhai KB, Jivani S. Suture haemorrhoidopexy and its short-term outcome. J. Evolution Med. Dent. Sci. 2018;7(53):5624-5628, DOI: 10.14260/jemds/2018/1244

\section{BACKGROUND}

Haemorrhoids are one of the commonly reported anorectal diseases in India and worldwide. Most of the patients present with advanced disease due to ignorance and fear of society. (Grade III or IV).[2]

'Financial or Other Competing Interest': None. Submission 19-11-2018, Peer Review 18-12-2018,

Acceptance 24-12-2018, Published 31-12-2018.

Corresponding Author:

Kalariya Bhargav Jerambhai,

Parishram,

\#5, Shaktinagar,

University Road, Rajkot-360005, Gujarat, India.

E-mail: drbhargavpatel2512@gmail.com

DOI: $10.14260 /$ jemds/2018/1244

\section{Treatment Options for Haemorrhoids-}

Conservative medical management with change of bowel habits, laxatives, pain relievers, anal spasm relievers.

Usually in patients with grade III \& grade IV haemorrhoids surgical management is preferred. Until last two decades, conventional surgical techniques such as Milligan Morgan's open haemorrhoidectomy and Ferguson's closed haemorrhoidectomy were considered to be "gold standard". Then in 1990s, stapled haemorrhoidopexy (SH), using a circular stapling instrument, was introduced by Dr. Antonio Longo and it became popular. [6],[7],[8]

In the new procedure as described by Chivate is a minimally invasive, painless, bloodless procedure without damaging sphincter. It is a modification of Stapler 
Haemorrhoidectomy (MIPH-Minimally Invasive Procedure for Haemorrhoids) and DGHAL (Doppler Guided Haemorrhoidal Artery Ligation with recto anal repair), but the procedure works on the same principle. The literature published before shows that it is patient friendly, minimally invasive and superior as compared to conventional haemorrhoidectomy and cost effective as compared to stapled haemorrhoidectomy. ${ }^{[9-13]}$

Suture Haemorrhoidopexy (Chivate's procedure) is a new invention by an Indian surgeon for managing 2nd, 3rd, 4th grades of haemorrhoids. It is based on the principles of blocking of blood supply and preventing the neo vascularization by plication of vessels in the rectum above dentate line at two different levels and anchoring the rectal mucosa \& sub mucosa to Parks Ligament.[5] In Relation to Superior Haemorrhoidal Artery, there are 3 anal Cushions at 3, 7 and 11'0 Clock Position. ${ }^{[14]}$ The main part of this cushion lies superior to the dentate line and which is covered by sensitive mucosa.[15] Cross section shows presence of sub mucosal layer consisting vessels, muscle fibers and connective tissue between internal sphincter and Anal Cushions. Fibroelastic collagen tissue and the muscular structure of Treitz (muscularis canalis ani) are the support of piles mass.[15] The venous plexus present in the form of sinusoids is known as 'corpus cavernosum of recti'.[16]

\section{Objective}

Objective of the study is to evaluate Chivate's new procedure of trans anal mucorectopexy for 3rd and 4th degree haemorrhoids for pain, bleeding, hospital stay, recurrence and complications.

\section{MATERIALS AND METHODS}

It is an observational study. A total no of 35 patients with grade 3 and grade 4 haemorrhoids (symptomatic with bleeding per rectum) underwent suture mucorectopexy procedure. The study was conducted at department of general surgery, SMIMER, Surat, wherein patients presenting to us with complaints of haemorrhoids were screened and patients with 3rd and 4th degree haemorrhoids and willing to undergo surgery were selected for this study. We had collected data of 35 patients with 3rd and 4th degree haemorrhoids and operated with this procedure. The sample size has taken for convenience.

The bowel was prepared using polyethylene glycol powder in 2 litre of water and making patient to drink it in 3$4 \mathrm{hrs}$. Under the spinal anaesthesia, patient was positioned in lithotomy along with head low position, which helped in reducing piles mass in grade II, III and IV cases and we get better visual field. The anal canal was lubricated with lignocaine jelly. A proctoscope along with its obturator was inserted into anal canal. Proctoscope has groove for fibreoptic scope in its handle. The obturator was removed. The dentate line was visualized. Stitches were started at three o'clock position at a distance of $4 \mathrm{~cm}$ proximal to the dentate line by passing through the depth of the mucus-submucous and part of muscle, for the stitch a polyglactin 1.0 on atraumatic $36 \mathrm{~mm} 1 / 2$ circle needle with $1.2 \mathrm{~m}$ length was used. Precaution was taken that stitch should pass only part of the rectal muscles. The first stitch was tied, and the next stitch was started 1-2 mm overlapping to the end of the first stitch, was double locked. To avoid purse sting effect, the double locking was continued for every stitch. The suturing was continued in the whole circumference of rectal mucosa at same level of first stitch. The second circumferential suture line was completed at $2 \mathrm{~cm}$ levels proximal to the dentate line. Because the suture lines were above the dentate line which has no somatic pain sensation so less pain incidences in the postoperative period. In short, only two circumferential suturing lines -one $4 \mathrm{~cm}$ and another $2 \mathrm{~cm}$ proximal to dentate line implemented in rectal mucosa.



\section{Inclusion Criteria}

Patients coming to surgical OPD with h/o per rectal bleeding and confirmed after routine investigations having grade II/III/ IV haemorrhoids with or without fissure of all age groups and both sexes were included in the study.

\section{Exclusion Criteria}

1. Patients with thrombosed pile, perianal hematoma, and ulcerated pile.

2. Anal stricture.

3. Proctitis.

4. Rectal sigmoid growth.

\section{Statistical Analysis}

The data were reported as mean \pm SD and frequency. The data collected was entered into Microsoft excel spread sheet and analysed using IBM SPSS Statistics, Version 22.

\section{Data Collection}

1. Detail history was taken.

2. Patients confirmed by $\mathrm{P} / \mathrm{R}$ and proctoscopic examination.

3. Post-operative period during in hospital stay, following data was collected.

4. Post-operative hospital stay.

5. Any complication if occurred.

6. Note was made of any complications.

The information collected was about grade, previous medical or surgical treatment and defecation symptoms before and after surgery, recurrence of symptoms.

All patients were operated under spinal anaesthesia (Bupivacaine Heavy 0.5\% 2.2-2.5 ml loading dose).

Various data was collected in term of time required for procedure, duration of hospital stay, return to normal activity, post-operative pain and other complication like perianal thrombosis, bleeding needing readmission, pain needing readmission, urinary retention, pruritus ani, mucosal prolapse, skin tags, constipation, tenesmus and recurrence.

Visual analogue scale was used for assessment of pain. (A score of 4 or more indicates severe pain).

All patients operated for mucorectopexy were called for follow up in OPD after 2 weeks, and then after 2 months.

\section{RESULTS}

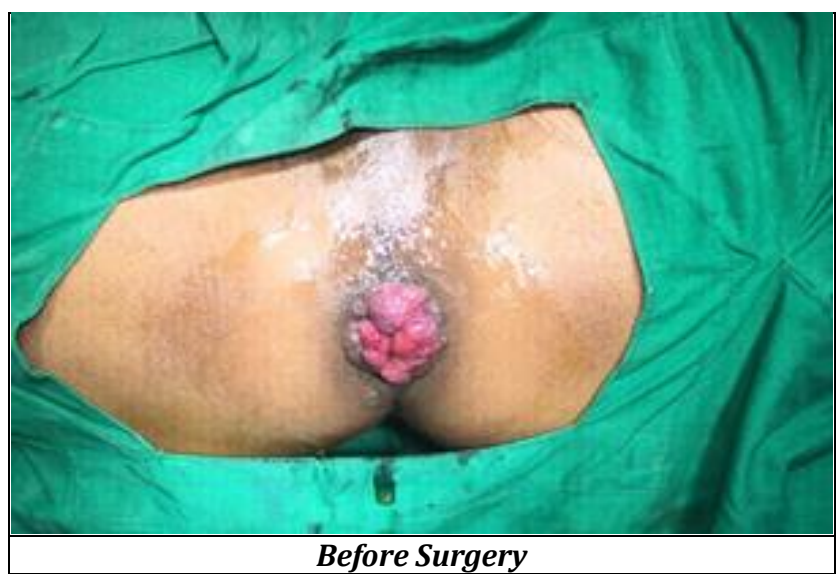

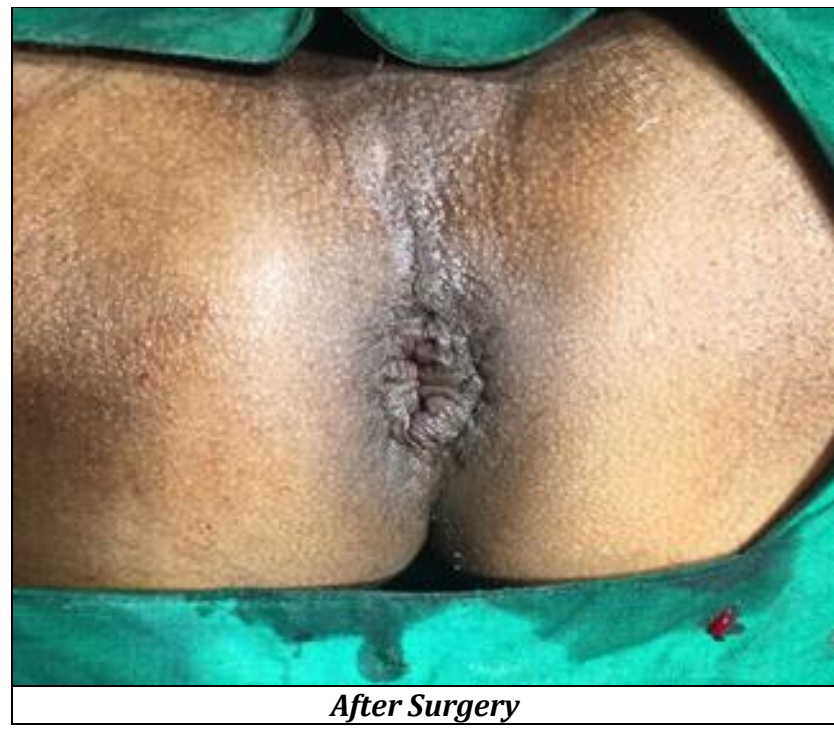

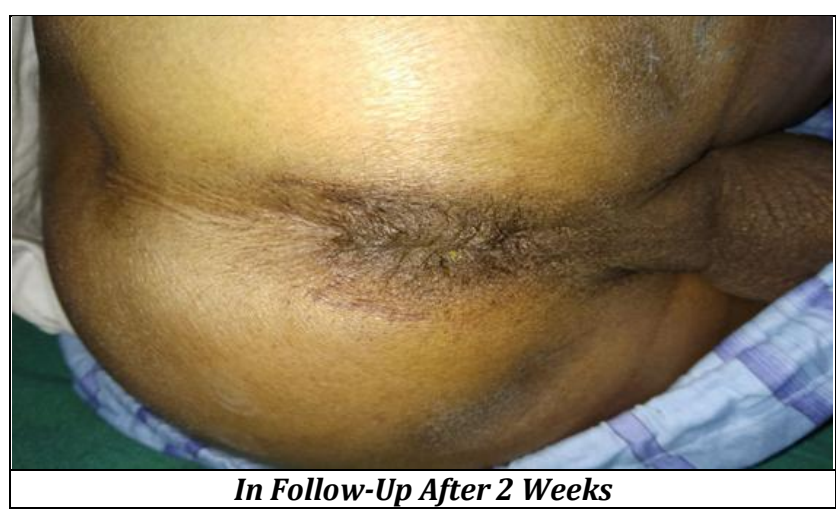

A total of 35 patients with haemorrhoids grade III and IV (symptomatic with bleeding per rectum) underwent suture haemorrhoidopexy procedure.

Out of 35 patients, $23(65.71 \%)$ were male and 12 (34.29\%) were female. In our study, $28.5 \%(n=10)$ patients had grade IV haemorrhoids and $71.5 \%(n=25)$ had grade III haemorrhoids. Total no. of patients with grade 3 piles was 20 and with grade 4 piles was 15 .

\begin{tabular}{|c|c|c|c|}
\hline & Grade 3 & Grade 4 & Total \\
\hline Male & 12 & 11 & $23(65.71 \%)$ \\
\hline Female & 8 & 4 & $12(34.29 \%)$ \\
\hline & 20 & 15 & 35 \\
\hline
\end{tabular}

Mean time required for procedure was 74.9 min with standard deviation of 4.82 .

Mean duration of hospital stay was 4.42 days with standard deviation of around 0.9 days.

Mean time to return to normal activity was 7.2 days with standard deviation of around 1.33 days.

Mean VAS (Visual analogue score) score for postoperative pain at 24 hours was 5.5 with standard deviation of around 0.7 , at 72 hours was 3.4 with standard deviation of around 0.5 , at 7 th day was 1.3 with standard deviation of around 0.3 , at 1 month was 0.3 with standard deviation of around 0.05 . 


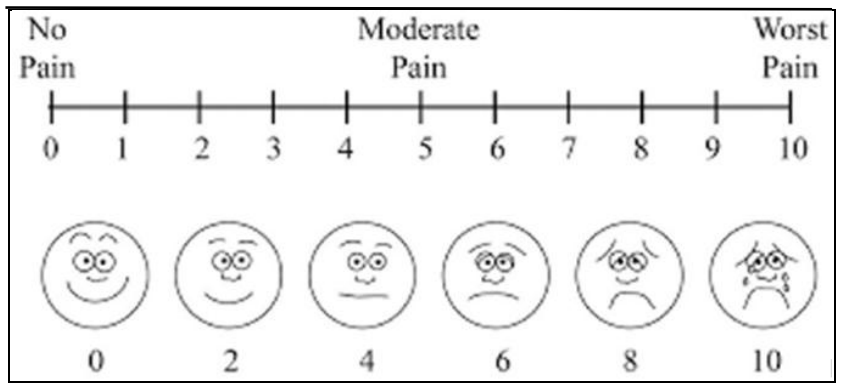

Commonly reported complaints include, urinary retention was $34.2 \%(n=12)$, pruritus ani $8.5 \%(n=3)$, bleeding PR in post-operative day $2.85 \%(\mathrm{n}=1)$, pain which required analgesic drugs injections $8.5 \%(n=3)$, constipation $2(n=2)$. One patient was presented on post-operative day 5 with urinary retention who required rehospitalization along with per urethral catheterization. There was no case of recurrence seen in 2 months of duration.

No patient had complaints of perianal hematoma, constipation, tenesmus, mucosal prolapse, or pain needing readmission.

\begin{tabular}{|c|c|c|}
\hline Complications & No. of Patients & Percentage \\
\hline Urinary Retention & 12 & 34.2 \\
\hline Pruritis & 3 & 8.5 \\
\hline Bleeding PR & 1 & 2.85 \\
\hline $\begin{array}{c}\text { Pain after Operation requiring } \\
\text { Analgesics }\end{array}$ & 3 & 8.5 \\
\hline Constipation & 2 & 5.71 \\
\hline Needed Rehospitalization & 1 & 2.85 \\
\hline Recurrence & 0 & - \\
\hline
\end{tabular}

In our study, out of 35 patients; 12 patients ( 7 males and 5 females) were having acute urinary retention in immediate post op period requiring urinary catheterization for same. This complication was arised may be due to post-operative pain, or may be due to effect of spinal anaesthesia and anal mucosal irritation, so further evaluation and studies are required to assess this complication by avoiding spinal anaesthesia and giving regional Perianal block/Pudendal block. Other recommendation is per urethral catheterization pre-operatively, and removed on first post-operative day.

In our study, $8.5 \%(\mathrm{n}=3)$ patients were having complaints of pruritus ani in post-operative period which was managed by simple cleaning by warm water. This complication may have been due to irritation of anal region by frequent in and out movement of instrumentation or maybe due to foreign body sensation of the suture (Vicryl sutures). In our study 2 patient had complain of constipation which was treated with giving laxative drugs for short term period.

In our study, we have not considered the cost of treatment.

\section{DISCUSSION}

Overall, suture haemorrhoidopexy (also known as trans anal mucorectopexy) is gaining popularity due to its cost effectiveness and better results. The clinical success of suture haemorrhoidopexy procedure is dependent on the surgeon's skills, adhering to the technical principles of suturing and right patient selection and it is found to be less painful with low recurrence and is patient friendly.

\section{CONCLUSION}

We have presented a short-term clinical outcome data of 35 patients. In spite of the limitations of the study, we can conclude that negligible recurrence rate on short term follow up along with lesser incidences of post-operative bleeding, minimal invasiveness with faster recovery or return to work will make Suture Haemorrhoidopexy as procedure of choice for grade II, III and IV haemorrhoids without complications.

\section{REFERENCES}

[1] Johanson JF, Sonnenberg A. The prevalence of haemorrhoids and chronic constipation. An epidemiologic study. Gastroenterology 1990;98(2):380-6.

[2] Ganz RA. The evaluation and treatment of haemorrhoids: a guide for the gastroenterologist. Clin Gastroenterol Hepatol 2013;11(6):593-603.

[3] Parks AG. De haemorrhoids: a study in surgical history. Guys Hosp Rep 1955;104(2):135-56.

[4] Antonietti SE, Rollinger G, et al. Doppler guided haemorrhoidal artery ligation. Am J Surg 2006;191(1):89-93.

[5] Chivate SD, Ladukar L, Ayyar M, et al. Transanal suture rectopexy for haemorrhoids: Chivate's painless cure for piles. The Indian Journal of Surgery 2012;74(5):412-7.

[6] Senagore AJ, Singer M, Abcarian H, et al. A prospective, randomized, controlled multicenter trial comparing stapled haemorrhoidopexy and Ferguson haemorrhoidectomy: perioperative and one-year results. Dis Colon Rectum 2004;47(11):1824-36.

[7] Milligan ETC, Morgan CN, Officer R. Surgical anatomy of the anal canal, and the operative treatment of haemorrhoids. Lancet 1937;11:119-24.

[8] Pavlidis T, Papaziogas B, Souparis A, et al. Modern stapled Longo procedure vs conventional MillganMorgan haemorrhoidectomy: a randomized controlled trial. Int J Colorectal Dis 2002;17(1):50-3.

[9] Longo A. Stapled anopexy and stapled haemorrhoidectomy: two opposite concepts and procedures. Dis Colon Rectum 2002;45(4):571-2.

[10] Herold A, Kirsch J, Staude G, et al. A German multicentre study on circular stapled haemorrhoidectomy. Colorectal Dis 2000;2:18.

[11] Morinaga K, Hasuda K, Ikeda T. A noveI therapy for nternal haemorrhoids: ligation of the haemorrhoidal artery with a newly devised instrument (Moricorn) in conjunction with a Doppler flowmeter. Am J Gastroenterol 1995;90(4):610-3.

[12] Sutherland LM, Burchard AK, Matsuda K, et al. A systematic review of stapled haemorrhoidectomy. Arch Surg 2002;137(12):1395-406.

[13] Bursics A, Morvay K, Kupcsulik P, et al. Comparison of early and 1-year follow-up results of conventional haemorrhoidectomy and haemorrhoid artery ligation: a randomized study. Int $\mathrm{J}$ Colorectal Dis 2004;19(2):176-80.

[14] Gibbons CP, Trowbridge EA, Bannister JJ, et al. Role of anal cushions in continence. Lancet 1986;327(8486):886-8. 


\section{Jemds.com}

[15] Haas PA, Fox TA, Haas GP. The pathogenesis of haemorrhoids. Dis Colon Rectum 1984;27(7):442-50.

\section{Original Research Article}

[16] Loder PB, Kamm MA, Nicholls RJ, et al. Haemorrhoids: pathology, pathophysiology and aetiology. Br J Surg 1994;81(7):946-54. 